\title{
Combination of pharmacotherapy and lidocaine analgesic block of the peripheral trigeminal branches for trigeminal neuralgia: a pilot study
}

\author{
Combinação de farmacoterapia e bloqueio analgésico com lidocaína sobre os ramos \\ periféricos trigeminais no tratamento da neuralgia do trigêmeo: um estudo piloto \\ Fabrizio Di Stani' , Christine Ojango², Demo Dugoni' , Luigi Di Lorenzo³, Salvatore Masala², Roberto Delfini , \\ Gianluca Bruti', Giovanni Simonetti², Elcio Juliato Piovesan ${ }^{4}$, Andrea Gennaro Ruggeri'
}

\begin{abstract}
Classical trigeminal neuralgia (CTN) is treated predominantly by pharmacotherapy but side effects and unsuccessful occurs. The current study was carried out to evaluate the therapeutic effect of combination of pharmacotherapy and lidocaine block. Thirteen patients with CTN managed with pharmacotherapy were recruited and assigned either to no additional treatment (Group I) or to additional analgesic block (Group II). The primary endpoint was the reduction in the frequency of pain episodes in a month assessed at 30 and 90 days. Comparisons of measurements of pain, general health and depression scales were secondary endpoints. The results from the follow-up visits at 30 and 90 days showed the Group II to have larger reduction in the frequency of pain and exhibited a bigger improvement in the scores of the pain, general health and depression scales. The results from this preliminary study suggest a clinical benefit of the combination of pharmacotherapy and lidocaine block.
\end{abstract}

Keywords: analgesic block, classical trigeminal neuralgia, lidocaine, treatment.

\section{RESUMO}

A neuralgia clássica do trigêmio (NTC) é tratada predominantemente por drogas, porém efeitos colaterais e falhas terapêuticas ocorrem. Avaliamos o efeito terapêutico da combinação entre farmacoterapia e bloqueio analgésico utilizando a lidocaína. Treze pacientes portadores de NTC tratados com farmacoterapia foram divididos em dois grupos: Grupo I pacientes que mantiveram somente tratamento medicamentos e Grupo II pacientes que associaram bloqueio anestésico. O objetivo primário do estudo foi à redução da freqüência da dor 30 e 90 dias após o bloqueio. Secundariamente avaliamos o impacto sobre as escalas de depressão, dor e qualidade de vida. 0 grupo II teve uma redução significativa na freqüência da dor e uma melhora nos escores de qualidade de vida, dor e escala de depressão. Os resultados sugerem um benefício clinico da combinação de farmacoterapia e bloqueio anestésico no tratamento da NTC.

Palavras-chave: bloqueio analgésico, lidocaína, neuralgia trigeminal clássica, tratamento.

Classical trigeminal neuralgia $(\mathrm{CTN})$ is a disorder characterized by recurrent unilateral brief electric shock-like pains, abrupt in onset and termination, limited to the distribution of one or more divisions of the trigeminal nerve and triggered by innocuous stimuli. There may or may not be, additionally, persistent background facial pain of moderate intensity. In general, the recurrent episodes prevail for a few seconds, although the duration of pain clusters may extend up to 2 minutes $^{1}$. The episodes are caused by trivial nonnociceptive stimuli, including eating, yawning, touching, feeling cold or warm ${ }^{2,3,4}$. The CTN patients describe "trigger zones" or specific facial areas, where these stimuli provoke pain $^{2}$. CTN developes without apparent cause other than neurovascular compression ${ }^{1}$.

The incidence of CTN is 4-5 per 100,000 persons per year and the disorder is more common in females over 50 years ${ }^{3,4,5}$.

The evidence of pressure to the trigeminal nerve from a vascular structure in CTN has been shown in various cases with imaging findings of artery crossing the nerve and/or provoking displacement ${ }^{3}$. In addition, intra-operative recordings

\footnotetext{
'University of Rome "La Sapienza”, Department of Neurology and Psychiatry, Neurosurgery A, Rome, Italy;

2University of Rome "Tor Vergata”, Department of Diagnostic and Molecular Imaging, Interventional Radiology and Radiation Therapy, Rome, Italy;

3“Rummo" Hospital, Rehabilitation Unit, Neuroscience Department, Benevento, Italy;

«Universidade Federal do Paraná, Hospital de Clínicas, Departamento de Clinica Médica, Especialidade de Neurologia, Curitiba PR, Brazil.

Correspondence: Fabrizio Di Stani; Via Sallustio Bandini, 10 - 00191; Rome Italy; E-mail: fdistani@gmail.com

Conflict of interest: There is no conflict of interest to declare.

Received 08 November 2014; Received in final form 19 March 2015; Accepted 08 April 2015.
} 
and the clinical improvement after de-compression are evidences of the presence of neurovascular conflict ${ }^{2}$. The pressure to the nerve is thought to cause de- and remyelination with the resulting of increased nerve excitability and manifestation of pain impulses ${ }^{3}$.

The first-line treatment for CTN pain is carbamazepine and oxcarbazepine ${ }^{6}$. Other anticonvulsants, such as lamotrigine, and the muscle relaxant baclofen are used as second-line therapy ${ }^{2}$. In about $30 \%$ of cases the pharmacological approach is not sufficient to control pain. The pharmacotherapy may produce side-effect, commonest being drowsiness, ataxia and decrease mental acuity ${ }^{5}$. The surgical management approaches include decompression of the trigeminal nerve or lesioning of the nerve or trigeminal ganglion². The choice of the surgical management depends on patient's age and co-morbidities, duration of symptoms and on the response to the pharmacotherapy, as procedure-related complications have been reported with sensory deficit being the most common ${ }^{6}$.

As an alternative management, trigeminal nerve block with local anaesthetics could be considered in combination with pharmacotherapy ${ }^{7,8}$. The scope of this study was to evaluate the clinical benefit of combination of pharmacotherapy and lidocaine analgesic block in CTN patients. Thus, this preliminary study attempts to generate hypotheses for future randomised controlled study to evaluate the efficiency of combination therapeutic approach in CTN pain management.

\section{METHOD}

\section{Study design and patients}

All subjects seen for the first time between may 2008 and september 2009 were recruited from the out-patient neurosurgery department of the general hospital of the University of Rome "La Sapienza". All enrolled patients were diagnosed with CTN according to the IHS 2004 criteria $^{9}$ and were retrospectively confirmed to be eligible according to IHS criteria $2013^{1}$. Patients with symptomatic trigeminal neuralgia were not included to the study. Additional exclusion criteria were age $<18$ years, diabetes mellitus or intolerance to glucose, cardiac arrhythmias, coagulation diseases, pregnancy or lactation and sensibility to lidocaine. Ethics committee approval was acquired before the start of the study and all patients gave written informed consent before the enrolment.

\section{Procedure}

All patients were started with or were already previously on the pharmacological therapy for the trigeminal neuralgia. Patients were randomly assigned to one of the two following treatment groups. Patients in Group I were treated over the whole study period only with pharmacological medications. In Group II, patients received in addition to their per os medication one injection of lidocaine to the trigger points. After the initial visit and conformation of eligibility, patients enrolled into Group II, were given the appointment for the analgesic block with lidocaine injection. The treatment procedure of analgesic block of the peripheral trigeminal branches was performed with 2-4 cc of $2 \%$ lidocaine. The injection was done in supine position with vertebral column in neutral position. After the application of the antiseptic on the area of interest, the injection with lidocaine was performed on one or on several levels of the exits of the three branches of the trigeminal nerve (V1, supraorbital foramen; V2, infraorbital foramen; V3, mandibular foramen). After the procedure patients were monitored for 1 hour for early complications and subsequently discharged from hospital.

\section{Evaluations}

The patients were assessed 3 times during the study duration. The first visit $(\mathrm{T}=0)$ was followed by a second visit at 30 days $(\mathrm{T}=1)$ and a third visit at 90 days $(\mathrm{T}=2)$ after the beginning or modification of the pharmacotherapy (Group I) or after lidocaine injection (Group II). The first visit $(\mathrm{T}=0)$ was consisted of the assessment of neurological status and the evaluation of pain and quality of life scales in patients eligible for the study. Baseline evaluations of routine blood tests, electrocardiography and neuroradiological evaluation with magnetic resonance and magnetic resonance angiography with arterial and venous phase were performed. The latter imaging data was acquired to exclude symptomatic trigeminal neuralgia and the final confirmation of eligibility was assessed according to the imaging data. During the follow-up visits $\mathrm{T}=1$ and $\mathrm{T}=2$ patients in both groups were assessed for the frequency of pain episodes in a month and with quality of life, depression and intensity of pain scales. The following scales as measures were recorded during the initial and the follow-up visits: The Medical Outcomes Trust 36-Item Short Form Health Survey (SF-36 $)$, Brief Pain Inventory (BPI) and Beck Depression Inventory (BDI). All of these scales have been well validated and used extensively in clinical trials and pain management.

\section{Case series analysis}

Descriptive statistics including mean and standard deviation (SD) were calculated for demographic and clinical characteristics of the study patients in both groups. The outcome measures for each patient was the frequency of pain attacks in a month measured at $\mathrm{T}=1$ and $\mathrm{T}=2$ and expressed as a percentage relative to the baseline $(0 \%$ - free from attacks; $100 \%$ same frequency of attacks as at baseline) and measures on the assessment scales. The patients were asked to report any adverse effects to the physician during the follow-up visits. 


\section{RESULTS}

Thirteen patients with classical trigeminal neuralgia, who met the IHS 2004 criteria $^{9}$, were recruited. All patients seen were offered to participate and none declined or dropped out. Seven patients were allocated to Group I, in which patients received only pharmacological treatment for CTN pain during the whole study duration. In Group II six patients underwent regional analgesic block of the peripheral trigeminal branches in addition to their pharmacotherapy. The general characteristics of patients in Group I and Group II are summarized in Table 1. Table 2 shows the results of the baseline assessments of SF-36, BPI and BDI scales separately in both groups. Pharmacotherapy was not the same in all the patients, although carbamazepine was the commonest drug prescribed to the study patients, followed by oxcarbazepine, gabapentin and lamotrigine.

At the first follow-up visit $(\mathrm{T}=1)$ at 30 days patients in Group I reported more pain episodes in a month (mean

Table 1. Baseline characteristics and clinical data of study patients.

\begin{tabular}{|c|c|c|c|c|c|}
\hline \multicolumn{6}{|c|}{ Demographic characteristics of study patients. } \\
\hline \multirow[b]{2}{*}{ Age (years) } & \multirow[b]{2}{*}{ Mean \pm SD } & \multicolumn{2}{|c|}{ Group I } & \multicolumn{2}{|c|}{ Group II } \\
\hline & & 63.0 & 11.8 & 68.2 & 10.8 \\
\hline Gender & Women n \% & 4 & 57.1 & 4 & 66.7 \\
\hline $\begin{array}{l}\text { Duration of symtoms } \\
\text { (years) }\end{array}$ & Mean \pm SD & 5.0 & 2.90 & 16.8 & 9.20 \\
\hline \multirow[t]{2}{*}{ Symtomatic facial side } & Right n \% & 2 & 28.6 & 3 & 50 \\
\hline & Left n \% & 5 & 71.4 & 3 & 50 \\
\hline \multirow{3}{*}{$\begin{array}{l}\text { Pain location } \\
\text { (trigeminal branches) V }\end{array}$} & V2 or V3 n \% & 3 & 42.9 & 3 & 50 \\
\hline & $1+\mathrm{V} 2$ or $\mathrm{V} 2+\mathrm{V} 3 \mathrm{n} \%$ & 4 & 57.1 & 2 & 33.3 \\
\hline & $V 1+V 2+V 3 n \%$ & 0 & & 1 & 16.7 \\
\hline $\begin{array}{l}\text { Frequency of pain } \\
\text { attacks }\end{array}$ & $\mathrm{dd} /$ month & 30 & & 28.3 & \\
\hline
\end{tabular}

SD: standard deviation; $n$ : number of patients; $d d /$ month: days per month.
$18.11 \pm 10$ ) than patients in Group II (mean $8.33 \pm 5, .16$ ). Similarly, during the second follow-up visit at 90 days there was an evident difference of frequency of pain attacks between Group I (mean 22.1 \pm 9.9) and Group II (mean 6.5 \pm 7.1 ). A side-by-side group comparison on individual subjects was made and the absolute frequency measures in follow-up studies were adjusted with baseline measurements in all patients, in order to visualise the residual pain. In Figure 1 the frequency of pain attacks in a month expressed as a percentage relative to the baseline ( $0 \%$ - free from attacks; $100 \%$ same frequency of attacks as at baseline) for all patients in both groups is shown. As seen in the Figure 1 patients in Group I had smaller pain frequency changes from the baseline in both follow-up visits, while patients in Group II the changes were bigger. The average of the frequency of pain attacks in a month expressed as a percentage relative to the baseline or residual pain in both groups is presented in Figure 2.

The results of SF-36, BPI and BDI scales showed the tendency of improved scores in the group who received the

Table 2. Baseline assessment of SF-36 ${ }^{\circledR}$, BDI and BPI scales.

\begin{tabular}{lcccc}
\hline & \multicolumn{2}{c}{ Group I } & \multicolumn{2}{c}{ Group II } \\
\cline { 2 - 5 } & Mean \pm SD & \multicolumn{2}{c}{ Mean \pm SD } \\
\hline SF-36 physical functioning & 50.7 & 35.76 & 66.7 & 26.39 \\
SF-36 physical role functioning & 25.7 & 36.56 & 25 & 38.73 \\
SF-36 bodily pain & 25.9 & 14.38 & 39.8 & 21.18 \\
SF-36 general health perceptions & 38.6 & 19.32 & 46 & 11.88 \\
SF-36 vitality & 43.1 & 18.37 & 50 & 14.83 \\
SF-36 social role functioning & 39.2 & 25.45 & 52 & 14.71 \\
SF-36 mental health & 34.3 & 25.81 & 60.7 & 19.66 \\
SF-36 emotional role functioning & 19.6 & 26.59 & 38.9 & 49.07 \\
BDI & 26.7 & 16.18 & 14 & 11.24 \\
BPI severity index & 5.1 & 1.999 & 5.3 & 2.558 \\
BPI interferference index & 4.3 & 1.599 & 3.4 & 3.354 \\
\hline
\end{tabular}

Baseline assessment of The Medical Outcomes Trust 36-Item; SF-36 ${ }^{\circledR}$ : Short Form, Health Survey; BDI: Beck Depression Inventory; BPI: Brief Pain Inventory scales.

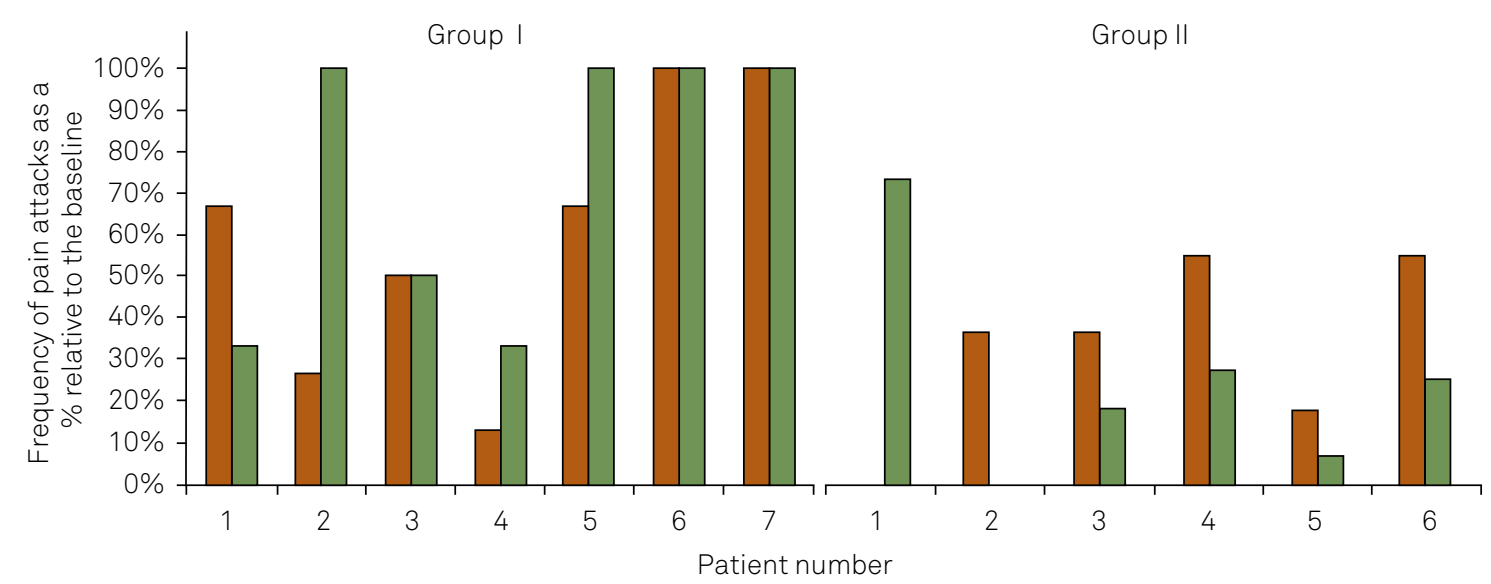

Figure 1. Frequency of pain attacks in a month measured at $T=1$ and $T=2$ expressed as a percentage relative to the baseline (0\%-free from attacks; $100 \%$ same frequency of attacks as at baseline) in all patients. Brown: follow-up visit T = 1 ; Green: follow-up visit T $=2$. 
combination treatment during both follow-up visits of $\mathrm{T}=1$ and $\mathrm{T}=2$. The Figure 3 represents the values of the assessment scales during the follow-up visit 30 days post-injection. Figure 4 represents the scores after 90 days. Group I had in all of the SF-36 sections smaller scores and in Group II the scores were higher, thus patients in Group II exhibited lesser disability and better emotional and physical functioning. Although, the BPI and BDI results did not differ remarkably, the tendency of lower depression and pain scores in Group II was noted. No systemic reactions were recorded and no injection-related adverse events of haematoma, itching or pain at the site of injection was reported.

Due to the small number of patients the statistical analysis was not done to evaluate the differences in frequency of pain episodes in a month and to evaluate the values of the assessment scales.

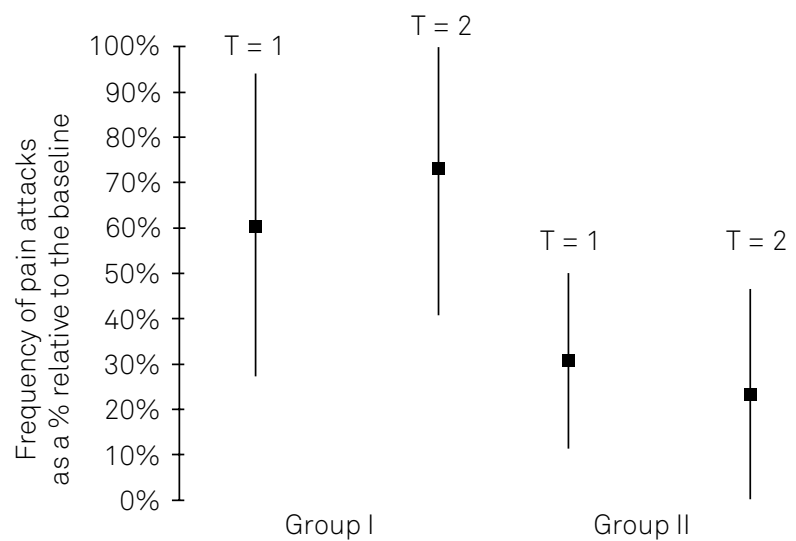

Figure 2. The average frequency of pain attacks in a month measured at $\mathrm{T}=1$ and $\mathrm{T}=2$ and expressed as a percentage relative to the baseline (0\%-free from attacks; $100 \%$ - same frequency of attacks as at baseline) in both groups.

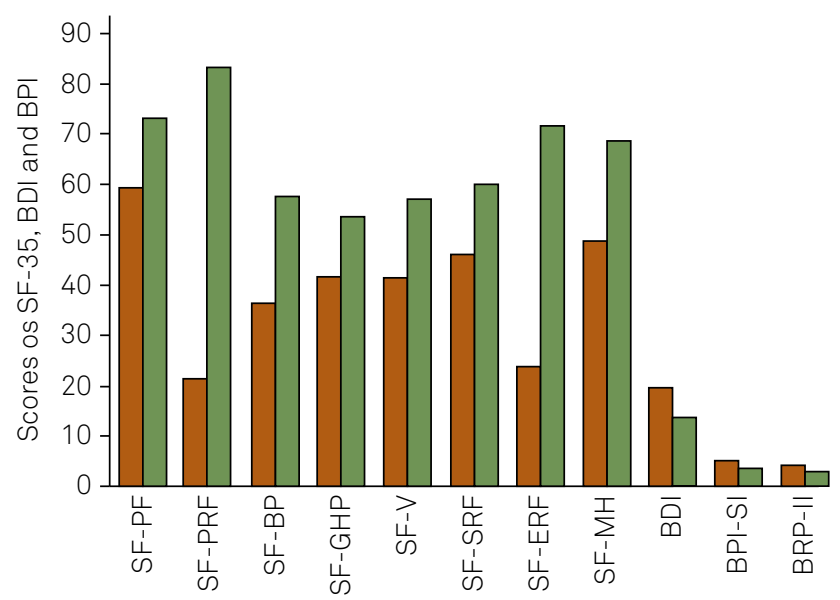

Figure 3. Assessment of scales at T = 1. Brown: Group I; Green: Group II. SF-36 dimensions: SF-PF - physical functioning, SF-PRF - physical role functioning, SF-BP - bodily pain, SF-GHP- general health perception, SF-V- vitality, SF-SRF - social role functioning, SF-ERF emotional role functioning, SF-MH - mental health, BDI- Beck Depression Inventory, BPI-SI - Brief Pain Inventory Severity Index, BPI-II - Brief Pain Inventory Interference Index.

\section{DISCUSSION}

The scope of the present study was to evaluate the efficacy of combination therapy of pharmacological treatment and the trigeminal nerve block with lidocaine in patients with classical trigeminal neuralgia. The previous studies with combination therapy of pharmacological treatment and analgesic injections for peripheral branches of the trigeminal nerve pain management have shown promising results. Han et al., evaluated high concentration of lidocaine for trigeminal nerve block in patients with $\mathrm{TN}^{7}$. Eleven of $35 \mathrm{pa}-$ tients in the cited study experienced complete pain relief and general pain scores following the analgesic block were markedly reduced compared to pre-treatment scores. The other study by Lemos et al. evaluated the protocol of gabapentin in association with ropivacaine block ${ }^{8}$. The clinical benefit in this combination management was found to be improvement of visual analogue scores (VAS) of pain until 28 days after the treatment. The results of the present study with injections of $2 \%$ lidocaine are in accordance with these previous studies of using local analgesic drug as a complementary treatment for pain management in CTN patients. Our study showed reduced frequency in both of the study groups, but more evident in the group which received the combination of pharmacological treatment and analgesic injection. In addition, in the present study patients treated with combination therapy presented in follow-up visits with improved quality of life (as assessed with several SF-36 ${ }^{\circ}$ scores), with less pain (as assessed with BPI scale) and with less depression (as assessed with BDI scores).

The effect of the combination therapy was evident in both follow-up studies of 30 days and 90 days. In clinical practice lidocaine is used as a local anaesthetic due to its rapid onset

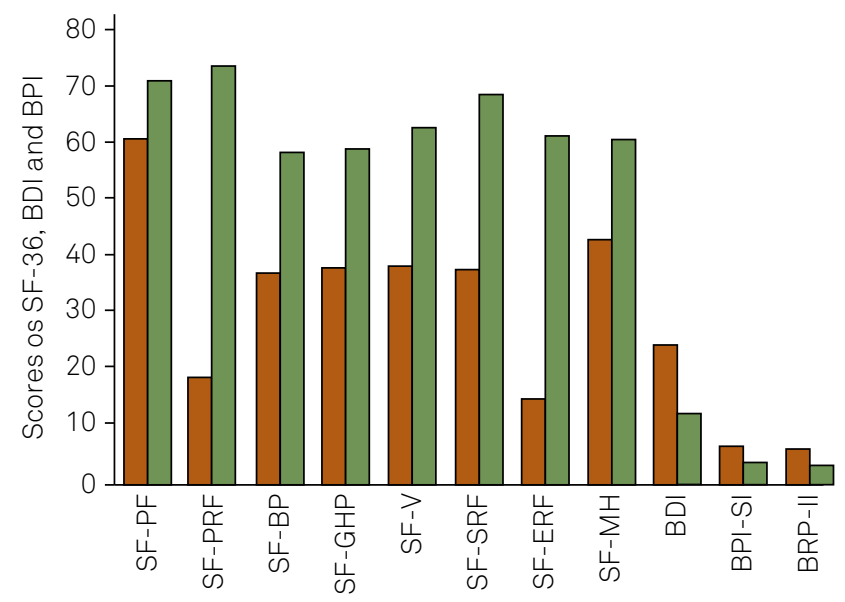

Figure 4. Assessment of scales at T = 2. Brown: Group I; Green: Group II. SF-36 dimensions: SF-PF - physical functioning, SF-PRF - physical role functioning, SF-BP - bodily pain, SF-GHP- general health perception, SF-V-vitality, SF-SRF - social role functioning, SF-ERF - emotional role functioning, SF-MH - mental health, BDI- Beck Depression Inventory, BPI-SI - Brief Pain Inventory Severity Index, BPI-II - Brief Pain Inventory Interference Index. 
and relatively short duration of the pharmacological action. The mechanism of the prolonged analgesic effect of the lidocaine injections, however, is not entirely clear. The prolonged effect of lidocaine injections on CTN has been described also in the study by Han et al. In that study the pain free interval after the nerve block was from 3 weeks up to 172 weeks ${ }^{7}$. The longer duration effect of the local analgesic is assumed to be partly due to the physical action of the analgesic drug by clearing adhesions or inflammatory exudates from the vicinity of the nerve?

Several limitations of the study should be mentioned. First, the study included a very small number of patients. This is due to fact that classical trigeminal neuralgia is relatively rare disorder. Furthermore, patients who were recruited from pain centers exhibited facial neuralgia symptoms already for many years. In standard clinical practice the first-line pharmacological medical treatment is offered for CTN patients and most of patients who were recruited had developed refractory to the first-line treatment. It would be of interest to evaluate the combination therapy also in the initial phase of the disease. Due to the small number of recruited patients into the study no specific statistical analyses was performed and the results were evaluated qualitatively as case series in this preliminary study. The qualitative results, however, are encouraging in order to set-up an extended study with randomised controlled trial.

In most $\mathrm{CTN}$ cases the pharmacological treatment is effective in the initial phase and the pharmacological treatment is usually maintained until it is effective. However, the pharmacological medication is not sufficient in all patients and over the course of the disease patients may develop refractoriness to the pharmacological treatment and often patients seek the alternative methods for their pain management. As the procedure of lidocaine analgesic injection is simple and safe, it can be recommended for patients, whose pain is not controlled sufficiently with only pharmacological drugs or to patients who have contra-indications for surgical intervention.

In conclusion, the combination of pharmacological therapy and lidocaine analgesic block of peripheral branches of the trigeminal nerve were able to achieve considerably lesser frequency of CTN pain attacks in a month than pain management with only the pharmacological therapy. In addition, to the reduction of frequency of CTN pain crises, the results showed consistent reduction of pain and improvement in the quality of life in the follow-up visits up to 90 days.

\section{References}

1. Headache Classification Committee of the International Headache Society (IHS). The International Classification of Headache Disorders, 3rd edition (beta version). Cephalalgia. 2013;33(9):629-808. http://dx.doi.org/10.1177/0333102413485658

2. Nurmikko TJ, Eldridge PR. Trigeminal neuralgia pathophysiology, diagnosis and current treatment. Br J Anaesth. 2001;87(1):117-32. http://dx.doi.org/10.1093/bja/87.1.117

3. Kleef M, Genderen WE, Narouze S, Nurmikko TJ, Zundert J, Geurts JW et al. Trigeminal neuralgia. Pain Pract. 2009;9(4):252-9. http://dx.doi.org/10.1111/j.1533-2500.2009.00298.x

4. Love S, Coakham HB. Trigeminal neuralgia: pathology and pathogenesis. Brain. 2001;124(12):2347-60. http://dx.doi.org/10.1093/brain/124.12.2347

5. Joffroy A, Levivier M, Massager N. Trigeminal neuralgia: pathophysiology and treatment. Acta Neurol Belg. 2001;101(1):20-5.
6. Obermann M. Treatment options in trigeminal neuralgia. Ther Adv Neurol Disorder. 2010;3(2):107-15. http://dx.doi.org/10.1177/1756285609359317

7. Han KR, Kim C, Chae YJ, Kim DW. Efficacy and safety of high concentration lidocaine for trigeminal nerve block in patients with trigeminal neuralgia. Int J Clin Pract. 2008;62(2):248-54. http://dx.doi.org/10.1111/j.1742-1241.2007.01568.x

8. Lemos L, Flores S, Oliveira P, Almeida A. Gabapentin supplemented with ropivacain block of trigger points improves pain control and quality of life in trigeminal neuralgia patients when compared with gabapentin alone. Clin J Pain. 2008;24(1):64-75. http://dx.doi.org/10.1097/AJP.0b013e318158011a

9. Headache Classification Subcommittee of the International Headache Society. The International Classification of Headache Disorders 2nd Edition. Cephalalgia. 2004;24 Suppl 1:9-160. 